\title{
Is Heritiera fomes Buch. Ham. less adapted to the present conditions of the Indian Sundarbans compared to other mangrove species?
}

\author{
P. Nandy (Datta)', M. Ghose', R. Spooner-Hart' and S. Das' \\ 'Agricultural and Ecological Research Unit, Indian Statistical Institute, 203, \\ B. T.Road, Calcutta 700 108, India: 'Centre for Plant and Food Sciences, University \\ of Western Sydney, Hawkesbury Campus (Building S8), Locked Bag 1797, Penrith \\ South DC, NSW 1797, Australia
}

\section{ABSTRACT}

Nandy(Datta), P., M. Ghose, R. Spooner-Hart and S. Das. 2006. Is Heritiera formes Buch. Ham. less adapted to the present conditions of the Indian Sundarbans compared to other mangrove species?Ann. Trop. Res. 28(2):76-91.

The Sundarbans forest forms one of the largest mangrove vegetation in the Bengal Basin. The name indicates dominance of the tree species Heritiera fomes Buch. Ham., locally known as 'Sundari' because of its elegance. Explosive demographic pressure and indiscriminate exploitation of natural resources caused imbalance in this ecosystem. Moreover, reduced fresh water influx and increased sedimentation appeared to be an increasing problem for navigation that in turn, led to elevated soil salinity. In the Indian part of this forest, scarcity of Heritiera fomes can be attributed to these manual and environmental adversities. In comparison to the other predominating species in Sundarbans, $H$. fomes is less equipped in its leaf anatomical adaptations and water-use management. Considerably thin cuticle and high stomatal frequency encourage water efflux; whereas, poorly developed water storage tissue and low frequency of terminal tracheioids weaken the water retention mechanism. This inefficiency is reflected well by the transpiration rate and stomatal conductance that continuously increase even beyond $1600 \mu \mathrm{mol} \mathrm{m}^{-2} \mathrm{~s}^{-1}$. In H. fomes, assimilation potential declines beyond $1250 \mu \mathrm{mol} \mathrm{m}^{-2} \mathrm{~s}^{-1}$ PAR, which unlike the other taxa, can be attributed to the poorly developed palisade tissue and low nitrogen content in leaf. The optimum leaf temperature for photosynthesis

Key words: Heritiera fomes, mangroves, metabolites, micromorphology, photosynthesis, Sundarbans, water use.

Correspondence:S. Das Present Address: Agricultural and Ecological Research Unit, Indian Statistical Institute, 203,B.T.Road, Calcutta 700 108, India Email:sauren@isical.ac.in

DOI: $10.32945 /$ atr2825.2006 
is $30^{\circ} \mathrm{C}$ that is considerably lower than that in the others. Osmotic potential $(\emptyset)$ of root and leaf is not low enough to facilitate water uptake from the extremely saline substrate; absence of free proline coupled with low $\mathrm{Na}+$ content explains the loss of turgidity in leaf cells. Reduced leaf $\mathrm{N}^{+}$may interfere the metabolic processes and hinder synthesis of the compatible solutes to some extent thus renders the species incompatible to the soil and microclimate of westem Sundarbans. On the verge of its extinction, these observations can help to chase up suitable strategies to restore the environment for $H$. fomes instead of unplanned plantation and wasting the propagules of this rare species.

\section{INTRODUCTION}

In the tropical and sub-tropical estuarine ecosystem, mangrove vegetation plays a vital role, as they are the natural transition between land and sea. Morpho-anatomy and physiological features of these plants point to adaptation against hostility of tidal influence and salt stress. To withstand the toxic effect of excess salinity, mangroves develop several lines of defense mechanisms in their micromorphology and metabolic processes. In highly saline substrate ion excess imposes osmotic stress and makes the soil physiologically dry for the inhabitant plants. To facilitate water uptake, mangrove roots and leaves have to maintain considerably low osmotic potential, which unlike the tropical rainforest trees would never be less negative than that of sea water $(-2.5$ $\mathrm{MPa}$ ) (Sperry et al., 1988). This osmotic adjustment is achieved by some compatible solutes deposited in the leaf cytosol and plenty of inorganic ions in the vacuoles (Greenway and Munns, 1980). Popp et al. (1984) estimated free proline, quaternary ammonium compounds, mannitol and cyclitols from 21 mangrove species in northern Queensland. Accumulation of such osmotica, especially in the cytosol, chloroplasts and mitochondria minimize water loss from the leaf cells due to water stress and/or high soil salinity (Heldt, 1999).

In a mangrove swamp, extreme irradiance so combines with high salinity that a constant but low assimilation rate is maintained throughout the day to avoid high light intensities, thus prevents photoinhibition (Nandy and Ghose, 2005). In order to control excess salt influx, mangrove roots take up water very slowly, primarily via symplastic pathway (Lin and Sternberg, 1993). In such a condition, high rate of transpiration may elevate the soil-bound salt concentration to such an extent that may severely hinder water uptake. On the other hand, when water flow is limited, rapid water efflux induces considerably 
low osmotic potential in the leaves that may strain the xylem cavity, leading to embolism (Ball and Passioura, 1993). At the threshold of desiccation, the cuticular layer is the ultimate barrier between plant and the atmosphere. Thus, constrains imposed to conserve water leads to restricted transpiration (Nandy and Ghose, 2005), leaf succulence, thick cuticular deposition and formation of water storage tissue (Das 1999). Hydrophobic nature of cuticular wax restricts the entry of saline water into leaves, while water storage is facilitated by terminal tracheoids at the vein endings (Rao, 1985; Das 1999). To reduce water efflux, mangrove leaves regulate stomatal conductance that in turn, does not encourage a high stomatal frequency. In Bruguiera parviflora, Parida et al. (2004) reported salt induced reduction of mesophyll and stomatal conductance that imposed restriction in assimilation rate. Photosynthesis increases with increase in temperature up to certain extent, but an abrupt rise in leaf temperature adversely affect the enzymatically catalysed reactions and membrane processes, leading to photoinhibition (Salisbury and Ross, 1995).

Salinity affects ion accumulation in leaves, thereby membrane permeability and chlorophyll synthesis. Increased accumulation of $\mathrm{Na}^{+}$is generally coupled with decline in carbon assimilation (Parida et al., 2004). $\mathrm{K}^{+}$plays a vital role in osmoregulation and protein synthesis, maintaining cell turgour and stimulating photosynthesis (Peoples and Koch, 1979); salt induced decline in $\mathrm{K}^{+}$content may cause damage to the photosynthetic apparatus (Chow et al., 1990).

In the Indo-Gangetic plain, Sundarbans forest forms one of the largest mangrove vegetations with a wide range of species diversity. In Indian Territory, the vegetation extends between $21^{\circ} 31^{\prime}$ to $21^{\circ} 31^{\prime} \mathrm{N}$ and $88^{\circ} 10^{\prime}$ to $89^{\circ} 51^{\prime} \mathrm{E}$. In western part the forest area covers approximately $2195 \mathrm{~km}^{2}$ (Sanyal, 1996) excluding the anastomosing network of creeks and backwaters. The soil salinity ranges between $15-27$ PPT, the maximum available irradiance is approximately $2000 \mu \mathrm{mol} \mathrm{m}^{-2} \mathrm{~s}^{-1}$ but the prevailing ambient temperature hardly rises above $38^{\circ} \mathrm{C}$ during summer (Das 1996); the average rainfall is $173 \mathrm{~cm}$ (Chanda and Datta 1986). The flora comprises 36 true mangroves, 28 associates and seven obligatory mangrove species representing 29 families and 49 genera (Naskar and Guha Bakshi, 1983). Unfortunately, excessive demographic pressure, over-harvesting for timber and fuel-wood production, poaching, reclamation for aquaculture and industrial pollution are being detrimental for this coastal resources. Since seventeenth century, damming on 
the lower Ganges cut off ample fresh water influx through Hooghly and its tributaries to the islands of Sundarbans. Besides, silting in the riverbed due to sewage and industrial pollution elevates the salinity level of water. In the western Sundarbans (the Indian part), these manual and environmental adversities proved disastrous for Heritiera fomes Buch. Ham., the key mangrove species (the name Sundarbans was derived from 'Sundari', the vernacular name of $H$. fomes) of the vegetation (Banerjee, 1999). This species predominates in between the Raimangal and Matla Rivers, where fresh water flows from the Ichamati River towards Raimangal. It prefers slightly and/or moderately saline zone and the ridges of higher elevation that are inundated only during spring tide (Alim, 1979). Previously in West Bengal these trees used to be $2 \mathrm{~m}$ in girth, but over $1 \mathrm{~m}$ girth are no longer common and top dying of $H$. fomes is frequent in the Sundarbans forest (Curtis, 1993).

Salinity varies both temporally and spatially in a mangrove swamp, but salt contents surrounding the roots change more slowly than does the microclimates (temperature, irradiance and precipitation) surrounding the leaves, which have a direct and immediate effect on diurnal water use in relation to carbon gain (Ball, 1988). In common practice, mangrove restoration management emphasizes only on planting as the primary tool rather than assessing the reasons for the loss of mangroves in an area (Lewis 2001). The present work aims to scrutinize some of the reasons behind gradual extinction of $H$. fomes from the western Sundarbans, where the other mangrove representatives thrive well. A few metabolic aspects were combined with some morphological characters, to explain the cumulative effect of these parameters towards comparative incompatibility of this species to high salinity forest bed of western Sundarbans.

\section{MATERIALS AND METHODS}

The investigation was based on six mangrove species under five different families, including Heritiera fomes. The other five taxa viz. Aegialitis rotundifolia, Avicennia officinalis, Bruguiera parviflora, Ceriops decandra and Xylocarpus mekongensis grow luxuriantly in the western Sundarbans. Comparative estimations and measurements between $H$. fomes 
and the other species are presented graphically and the data represents the average of ten observations from each of the ten studied plants in each taxa.

\section{Leaf anatomy}

Leaf anatomy was studied from thin transverse sections stained by Fluorrescein diacetate (FDA)(Michael et al. 1999) under a fluorescence microscope (Zeiss, Axiolab MC $80 \mathrm{DX}$ ). Epidermal peeling of mature leaves were studied under microscope and stomatal counts were recorded per mm2. Small pieces of lamina were soaked overnight at $30 \%$ nitric acid at room temperature $\left(25^{\circ}-28^{\circ} \mathrm{C}\right)$ to isolate and bleach the mesophyll. The meshwork of veins was teased out of the loosened matrix and stained with $0.5 \%$ toluidine blue-o. Shapes and frequency of terminal tracheoids at the vein endings were studied under microscope.

\section{Physiological parameters}

1. Photosynthesis and transpiration were measured in situ under broad day light condition ( 800 - $2000 \mu$ mol photons $\mathrm{m}^{-2} \mathrm{~s}^{-1} \mathrm{PAR}$ ) using an infrared $\mathrm{CO}_{2}$ Gas Analyser (PS 301 CID, USA) equipped with an open chamber. Measurements were taken from the exposed surface of leaves from top, middle and bottom of each plant. The rate of net photosynthesis $\left(P_{n}\right)$ was determined measuring the rate, at which a known leaf area assimilated $\mathrm{CO}_{2}$ concentration at a given time.

$$
\begin{gathered}
P_{n}=-W \quad\left(C_{o}-C_{p}\right)=-2005.39 \quad\left\{\left(\begin{array}{ll}
V & P
\end{array}\right) /\left(T_{a} A\right)\right\} \quad\left(C_{o}-C_{P}\right) \ldots \ldots \ldots \\
{\left[\mathrm{Co}\left(\mathrm{C}_{1}\right)=\text { outlet (inlet) } \mathrm{CO}_{2} \text { conc. }\left(\mathrm{mol} \mathrm{m}^{-2} \mathrm{~s}^{-1}\right) \text { and } \mathrm{T}_{\mathrm{a}}=\text { air temp. }(\mathrm{K})\right] .}
\end{gathered}
$$

Transpiration rate $(\mathrm{E})$ was measured from the water vapour flux per one-sided leaf area.

$$
E=\left\{\left(e_{o}-e_{p}\right) /\left(P-e_{0}\right)\right\} W 10^{3} \ldots \ldots \ldots\left[e_{o}\left(e_{p}\right)=\right.\text { outlet (inlet) water }
$$
vapour (bar); $\mathrm{P}=$ atm. pressure (bar) and $\mathrm{W}=$ mass flow rate per leaf area $\left.\left(\mathrm{mmol} \mathrm{m} \mathrm{s}^{-1}\right)\right]$. 
2. Osmotic potential (Ø) was estimated from cell sap of the freshly collected tissues. Filtered extracts from root and leaf were centrifuged at 3000 $\mathrm{rpm}$ for half an hour and volume of the supernatant was made up to $25 \mathrm{cc}$ with deionised water. Specific conductivity was measured at room temperature $\left(23^{\circ} \mathrm{C}\right)$ with a conductivity meter (Systronics, Direct Reading Conductivity Meter 304) and the value was converted to osmotic potential (OP) following the formula:

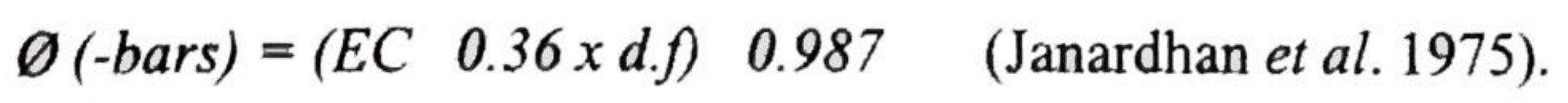

[EC $=$ Electrical conductance $\left(\operatorname{mmhos} \mathrm{cm}^{-2}\right)$ of the plant extract at $23^{\circ} \mathrm{C}$; d.f $($ dilution factor $)=\{25 \mathrm{cc}$ (filtrate) $\times \lg ($ fresh weight $)\}$ moisture content $\mathrm{g}^{-1}$ leaf tissue (fresh wt-dry wt) and $0.987=$ factor for converting atmospheric pressure into bars].

3. Free proline and alanine contents were estimated by thin layer chromatography of fresh leaf sap homogenised with $80 \%$ ethanol. The spots were eluted with acetone and quantified spectrophotometrically (He $\lambda$ ios 7.03 ) at 500 and $450 \mathrm{~nm}$ for proline and alanine respectively.

4. Sodium and potassium contents of leaf were estimated flame photometrically (Systronics 128) (Volhard, 1956) and leaf nitrogen was measured by Kjeldal-digestion method (Jackson, 1973). The data presented for each aspect is the average of ten observations/replications estimated from three different plants.

\section{RESULTS}

\section{Leaf anatomy}

Leaves are dorsiventral with hairy appendages in Aegialitis rotundifolia, Avicennia officinalis and Heritiera fomes. In A. rotundifolia glandular hairs wrap the leaf on both the surface, in A. officinalis glandular hairs traverse both upper and lower surface while non-glandular hairs are confined to the abaxial surface only, in $H$. fomes stellate non-glandular hairs covers the abaxial surface of the lamina (Figs. 1A, B, E). The other species are devoid of such 
Table 1. Micromorphological parameters of leaf, a comparative study

\begin{tabular}{lllll}
\hline Name of the Species & \multicolumn{3}{l}{ Measured parameters } \\
\cline { 2 - 5 } & $\begin{array}{l}\text { Cuticle } \\
\text { thickness } \\
(\mathrm{mm})\end{array}$ & $\begin{array}{l}\text { Colourless } \\
\text { zone ratio } \\
\left(\mathrm{T}_{1} \mathrm{~T}\right)\end{array}$ & $\begin{array}{l}\text { Stomata } \\
/ \mathrm{mm} 2\end{array}$ & $\begin{array}{l}\text { Terminal } \\
\text { tracheids } \\
/ \mathrm{cm}^{2}\end{array}$ \\
\hline A. rotundifolia & 0.07 & 1.43 & 146 & 200 \\
& $(0.42)$ & $(0.91)$ & $(1.7)$ & $(0.81)$ \\
A. officinalis & 0.08 & 0.24 & 277 & 156 \\
& $(0.6)$ & $(0.32)$ & $(0.05)$ & $(1.72)$ \\
B. parviflora & 0.06 & 0.27 & 134 & 130 \\
& $(0.28)$ & $(0.11)$ & $(1.58)$ & $(1.08)$ \\
C. decandra & 0.09 & 0.14 & 147 & 120 \\
& $(0.98)$ & $(0.87)$ & $(2.42)$ & $(0.3)$ \\
H. fomes & 0.03 & 0.1 & 646 & 84 \\
& $(0.76)$ & $(0.64)$ & $(0.06)$ & $(0.79)$ \\
X. mekongensis & 0.04 & 0.63 & 643 & 192 \\
& $(0.3)$ & $(0.76)$ & $(1.61)$ & $(1.66)$ \\
\hline
\end{tabular}

N.B. Values within parentheses indicate \pm standard errors.

hairs, thus non-secretors. Stomata are sunken with outer ( $A$. officinalis, $H$. fomes and $X$. mekongensis) or both inner and outer ( $A$. rotundifolia, $B$. parviflora and $C$. decandra) cuticular outgrowth (ledges) of the aperture (Fig. 1). Stomatal frequency ranges between $134-646 \mathrm{~mm}^{-2}$, the highest number been counted in $H$. fomes. Cuticle is smooth except in $A$. rotundifolia, the thickness ranges from 0.03 to $0.07 \mathrm{~mm}$ with the minimum thickness in $H$. fomes (Table 1). The uni- to multiseriate hypodermis acts as the water-storage tissue, the thickness being minimum in $H$. fomes (Table 1 ). In comparison to the other species mesophyll tissue is poorly developed in $H$. fomes due to its loosely arranged bi-layered palisade cells (Fig 1). In H. fomes sclerotic bundles are frequently extended from hypodermis to the lower epidermis that makes the leaf coriacious. In all the studied species, vein endings are appended with terminal tracheids of varied structures and frequency (Table 1), the latter being lowest in $H$. fomes. 


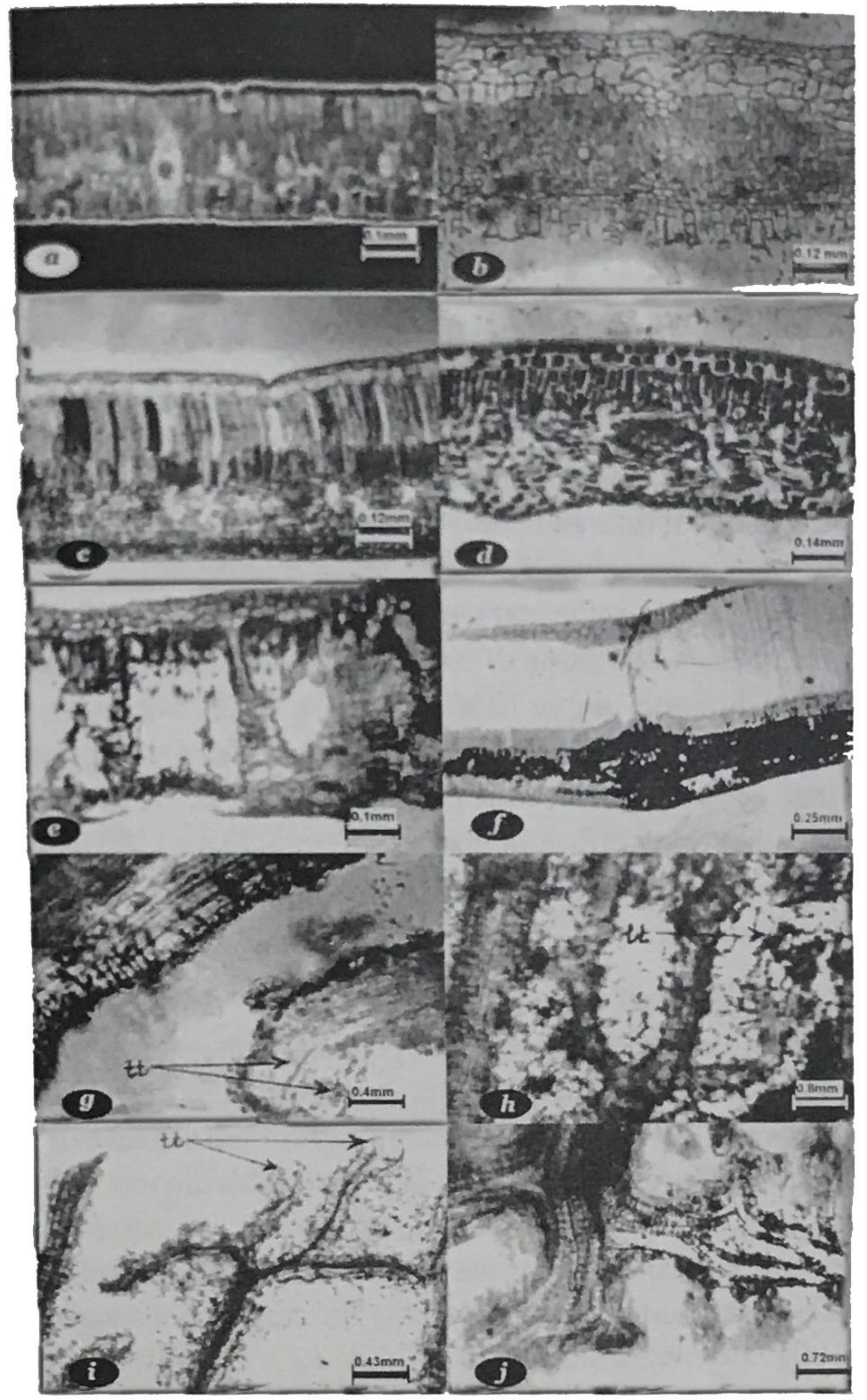

Fig. 1. a - j Photomicrographs of leaf micromorphology; a - f transverse sections of the leaf, a - Aegialitis rotundifolia, b - Avicennia officinalis, c - Bruguiera parviflora, d - Ceriops decandra, e - Heritiera fomes, f - Xylocarpus mekongensis; $\mathrm{g}$ - j photomicrographs of leaf vein endings showing terminal tracheoids (tt); $\mathrm{g}$ - Avicennia officinalis, $\mathrm{h}$ - Bruguiera paniflora, $\mathrm{i}$ - Heritiera fomes, $\mathrm{j}$ - Xylocarpus mekongensis. (Measurements are denoted on the figure itself as conversion of $1 \mathrm{~cm}$ bar). 


\section{Carbon assimilation and water efflux}

The rate of net photosynthesis rises up to certain PAR, and then declines gradually. Amongst the studied species, the maximum photosynthesis rates range between $9.5-17.9 \mu \mathrm{mol} \mathrm{m}^{-2} \mathrm{~s}^{-1}$, the highest value been measured in $A$. officinalis (Fig. 2A). The optimum PAR requirement at the assimilation peak varies from 1250 to $1490 \mu \mathrm{mol} \mathrm{m}^{-2} \mathrm{~s}^{-1}$, though the available irradiance is often as high as $2000 \mu \mathrm{mol} \mathrm{m}^{-2} \mathrm{~s}^{-1}$ in the Sundarbans forest. In all the studied taxa leaf temperature exceeds ambient temperature due to restricted transpiration rate and the range of threshold temperature is $30.9^{\circ}-37.2^{\circ} \mathrm{C}$ beyond which photosynthesis declines (Fig. 2D). In H. fomes photosynthesis drops beyond $1250 \mu \mathrm{mol} \mathrm{m}^{-2} \mathrm{~s}^{-1}$ PAR as the leaf temperature exceeds $30.9^{\circ} \mathrm{C}$ (Fig. 2D). In most of the species, the slope of transpiration and stomatal conductance increases considerably above $1250 \mu \mathrm{mol} \mathrm{m}^{-2} \mathrm{~s}^{-1} \mathrm{PAR}$, but declines beyond $1340-1590 \mu \mathrm{mol} \mathrm{m}^{-2} \mathrm{~s}^{-1}$ (Figs. 2B, C). In B. parviflora transpiration drops earlier, just beyond $1280 \mu \mathrm{mol} \mathrm{m}^{-2} \mathrm{~s}^{-1}$ whereas, in $H$. fomes stomatal conductance and water efflux hardly reduce even above $1590 \mu \mathrm{mol} \mathrm{m}^{-2} \mathrm{~s}^{-1}$.

\section{Chemical analysis}

In Sundarbans, salinity ranges between 15-27 PPT in soil and 23-26 PPT in water. In the studied taxa, osmotic potential of the root sap vary between -0.63 to $-2.53 \mathrm{MPa}$ and that of the leaf between -2.58 to $-5.31 \mathrm{MPa}$ (Fig. $2 \mathrm{E})$. Both root and leaf $\mathrm{OP}$ are considerably higher (less negative) in $H$. fomes, -0.71 and $-2.58 \mathrm{MPa}$ respectively (Fig. 2E). Detectable amount of free proline is present only in A. rotundifolia, A. officinalis, B. parviflora and $X$. mekongensis (Fig. 2G). Amongst the inorganic elements studied in leaf cells, (available nitrogen, sodium and potassium) $\mathrm{Na}^{+}$content is the highest $(0.224$ -

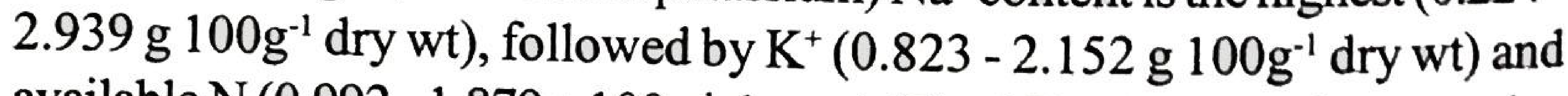
available $\mathrm{N}\left(0.992-1.879 \mathrm{~g} \mathrm{100g}^{-1} \mathrm{dry} \mathrm{wt}\right)(\mathrm{Fig}$. 2F). Heritiera fomes retains

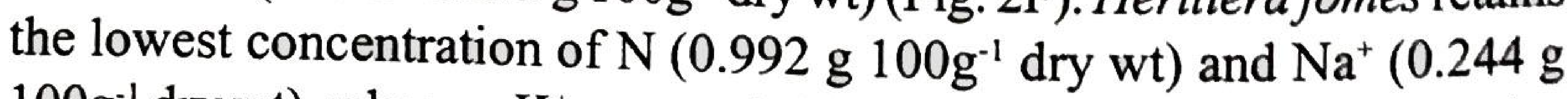
$100 \mathrm{~g}^{-1}$ dry wt), whereas $\mathrm{K}^{+}$content is higher than the other studied species (Fig. 2F). 

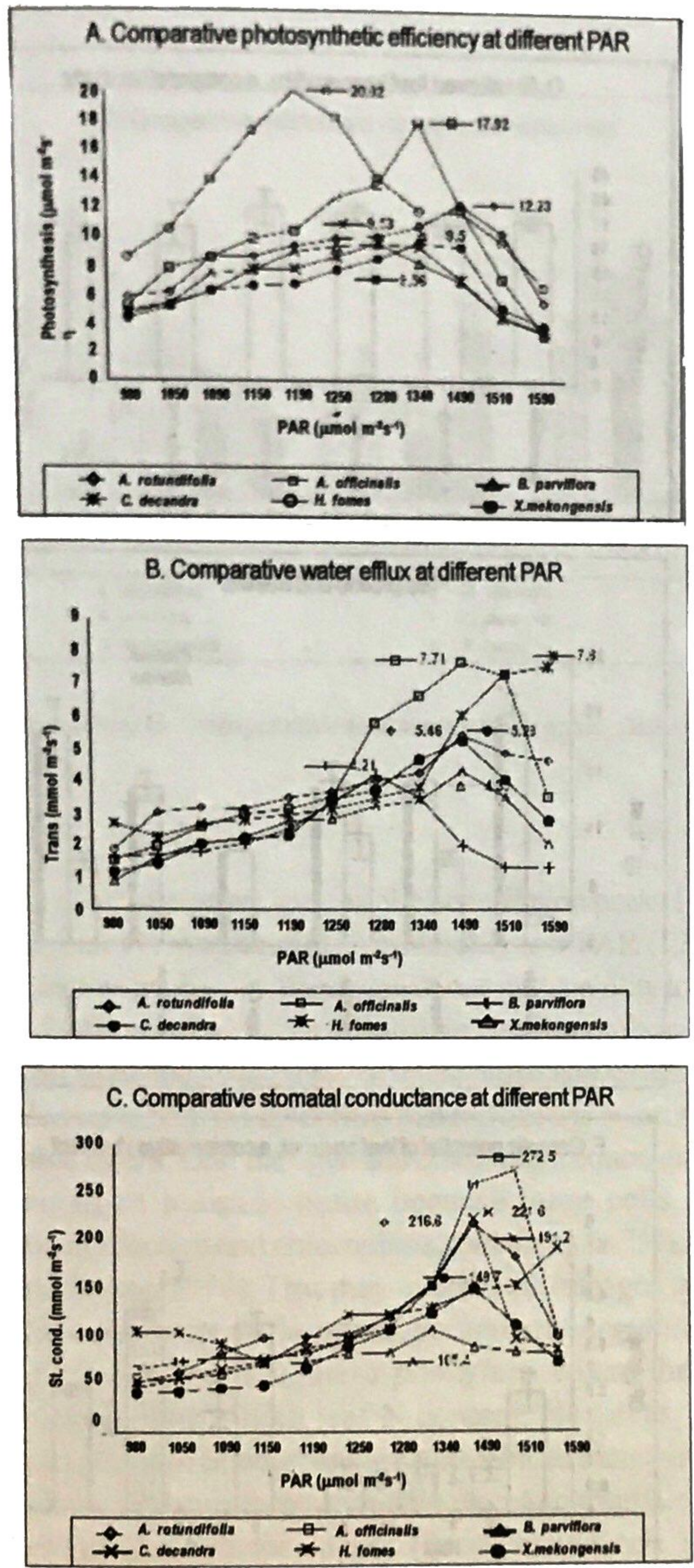

Fig. 2. A - F. Graphical presentations of some physiological parameters, a comparative approach. A - Photosynthetic efficiency at different PAR B - Transpiration rates at different PAR C - Stomatal conductance at different PAR 

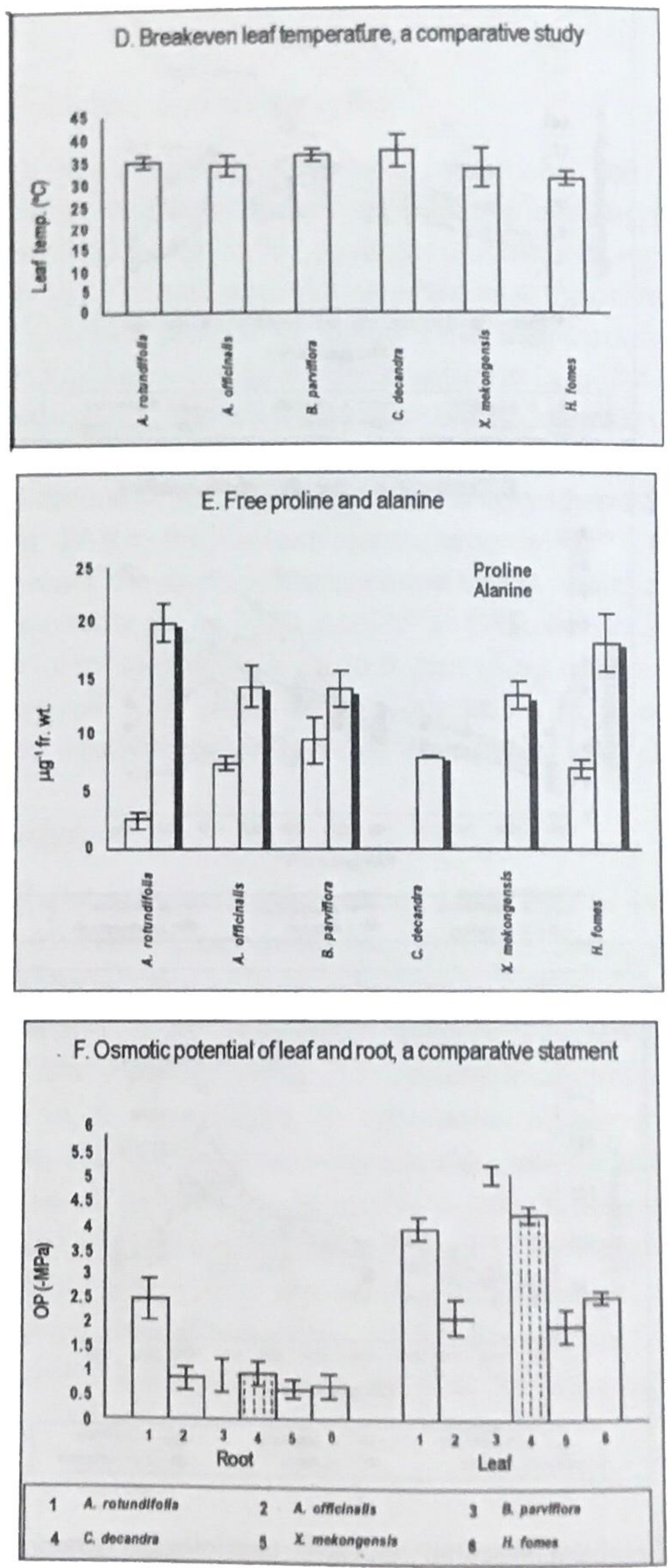

Figure 2 (continuation) D - Break even leaf temperatures $\mathrm{E}$ - Estimation of free proline and alanine. 


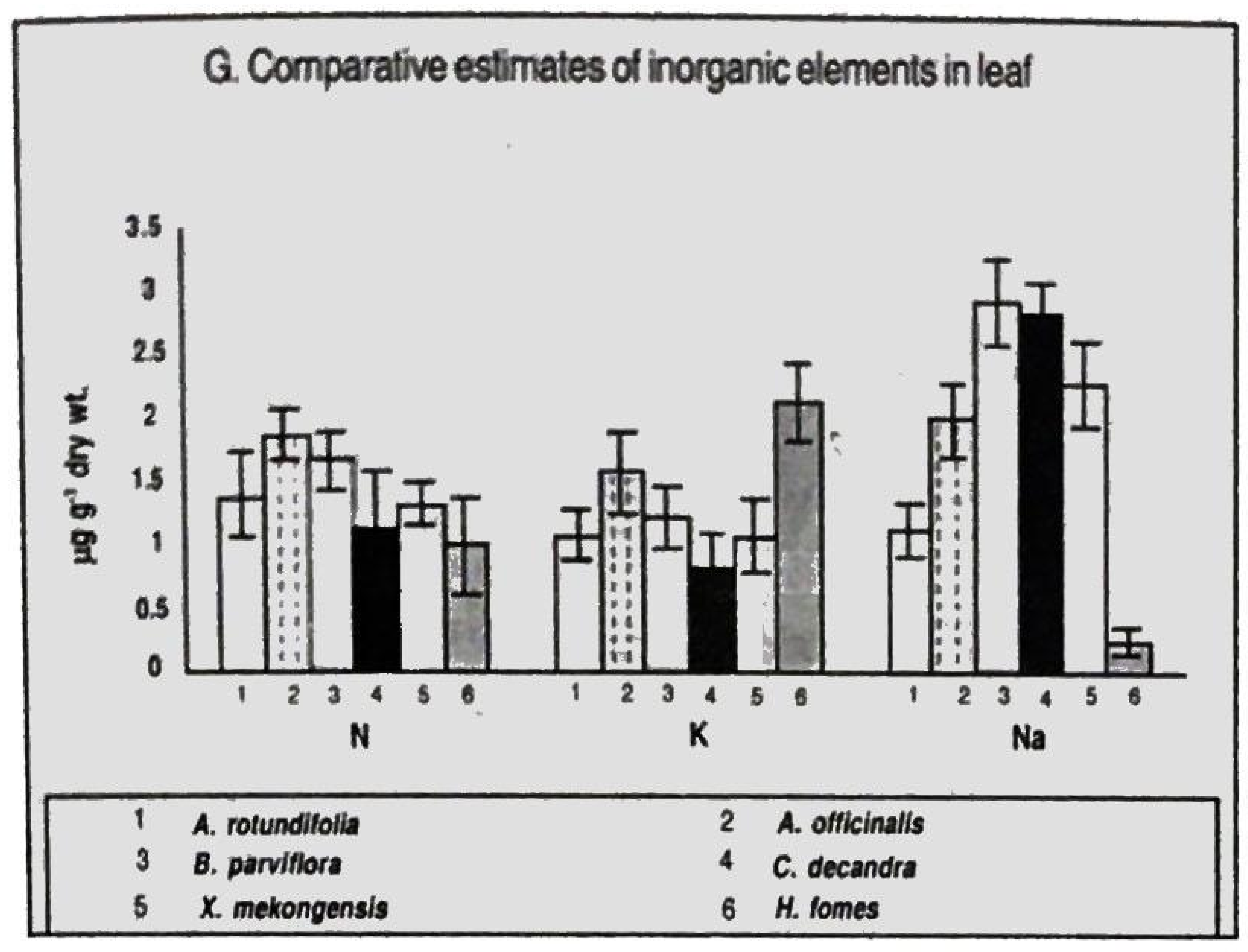

Figure 2. (continuation) $\mathrm{G}$ - comparative estimates of inorganic elements in leaf.

\section{DISCUSSION}

Unlike in other mangrove species, the assimilation peak $(14.7 \mu \mathrm{mol} \mathrm{m}-2 \mathrm{~s}$ ') in Heritiera fomes is measured at considerably low PAR $\left(1250 \mu \mathrm{mol} \mathrm{m}^{-2} \mathrm{~s}^{-}\right.$ ') and further decline in photosynthesis questions its capability to utilize the full irradiance $\left(\sim 2000 \mu \mathrm{mol} \mathrm{m}^{-2} \mathrm{~s}^{-1}\right)$ available in the Sundarbans forest. Such inefficiency can be attributed to plenty of intercellular spaces and a huge bundle sheath extended up to both the epidermis that replace the chlorophyllous tissue to a considerable extent. Leaf nitrogen and chlorophyll concentrations increase with the amount of palisade tissue because these cells are primarily photosynthetic in function and chloroplasts contain up to $75 \%$ of leaf organic $\mathrm{N}$ (Poorter and Evans, 1998). This may explain the nitrogen starvation in $H$. fomes leaves in comparison to the others, particularly Aegialitis rotundifolia, Avicennia officinalis and Bruguiera parviflora where the well-formed mesophyll couples with a high leaf $\mathrm{N}$ content. However, most of these predominating species of Sundarbans are incapable to maintain a consistently high rate of photosynthesis throughout the day. Accumulation of $\mathrm{K}^{+}$in leaf cells enhances the rate of photosynthesis (Peoples and Koch, 1979), whereas $\mathrm{Na}^{+}$rich leaves are less efficient in carbon assimilation (Parida et al., 2004). In leaves of the studied taxa, the salt induced decline in $\mathrm{K}^{+}$content may damage 
the photosynthetic apparatus as also reported earlier by Chow et al. (1990) thereby, affects assimilation rate to some extent.

At extremely high temperature, the metabolic enzymes become denatured, and ATP and $\mathrm{NADPH}^{+}$are not produced fast enough to allow increase in $\mathrm{CO}_{2}$ fixation, thus leading to a rapid decrease in the rate of photosynthetic process (Heldt, 1999). In H. fomes, leaf temperature does not rise as high as the other ones due to elevated transpiration rate; nevertheless, the threshold leaf temperature is considerable low $\left(30^{\circ} \mathrm{C}\right)$ in comparison to most of the others, which can tolerate as high as $35^{\circ}-37^{\circ} \mathrm{Cleaf}$ temperature. Resistance to water efflux through solid cuticle on the stomatous leaf surface is about 11 times lower than cuticular resistance on the astomatous one (Šantrucek et al., 2004). In H. fomes, comparatively thin cuticle coupled with the highest stomatal frequency and consistently high stomatal conductance contributes to uncontrolled water efflux even at a high PAR (above $1590 \mu \mathrm{mol} \mathrm{m}^{-2} \mathrm{~s}^{-1}$ ). Unlike others, the bi-layered poorly developed water storage tissue gets into the way of leaf succulence that makes the plant incompatible to the highly saline and physiologically dry soil of western Sundarbans. Terminal tracheoids are involved in capillary water storage (Zimermann, 1983) and these vein-ending characters synchronize with xerophytic adaptation (Rao, 1985). In H. fomes, fewer number of terminal tracheoids points to inefficient adaptation in the Sundarbans soil.

In Sundarbans, enhanced salinity renders the osmotic potential of soil about $-2 \mathrm{MPa}$. In most of the species, a reverse trend has been observed between leaf $\mathrm{OP}$ and the amount of water storage tissue. Ample water content in leaf probably owes to the high (less negative) osmotic potential and viceversa. In $H$. fomes however, the root and leaf $\mathrm{OP}$ are not low enough to encourage easy water uptake from the extremely saline substrate. Nitrogen, being the key element of proteins and amino acids, is deposited at a considerably low amount in leaves of this species that may affect the metabolic processes, particularly synthesis of free proline, that act as compatible solutes to retain low leaf OP under salt stress (Popp et al., 1984; Nandy and Ghose, 2003). Nandy and Ghose (2003) reported a complementary relation between free proline and alanine in mangroves, where absence or less proline content is coupled with elevated alanine concentration and vice-versa. Absence of proline may represent an adaptive lag in $H$. fomes. Unlike others, low $\mathrm{Na}^{+}$content in 
leaf may be another inefficiency of this species to thrive under salt stress.

Interactive effects of salinity and light occur on photosynthesis of mangroves when high salinity reduces the capacity for photosynthetic carbon assimilation under high irradiance (Björkman et al., 1988). The present study reveals at least a few inherent factors in $H$. fomes that are incompatible to high salinity and irradiance, both anatomical and physiological. A well-drained, low saline soil with moderate $\left(1000-1250 \mu \mathrm{mol} \mathrm{m}^{-2} \mathrm{~s}^{-1}\right)$ PAR and temperature (approx. $30^{\circ} \mathrm{C}$ ) is best suited for $H$. fomes. Nitrogen however, does not obey the rule of 'luxury consumption' unlike $\mathrm{K}^{+}$. Unlike the other studied species, $H$. fomes actually grows best at a substrate salinity of 7 - 10 PPT, but has to cope with 15 - 27 PPT salinity in the present situation of Indian Sundarbans, thus declines gradually. Keeping the observations in mind proper strategies should be chalked out to restore its environment, i.e. soil and microclimate to replenish this threatened species from the disastrous impact of increased salinity instead of mere planting and wasting the propagules of the endangered taxa.

\section{REFERENCES}

ALIM, A. 1979. Instruction manual for plantations in coastal areas. In: Research considerations in coastal afforestation (White, K. L. ed.). Food and Agricultural Organization, UNDP/FAO Project BDG/72/005. Chittgong, Bangladesh: Forest Research Institute. 65 - 75 pp.

BANARJEE, L. K. 1999. Mangroves of Orissa coast and their ecology. Bishen Singh Mohendra Pal singh, Dehra Dun. 41pp.

BALL, M. C. 1988. Ecophysiology of Mangroves. Trees 2: 129 - 142.

BALL, M. C. , J. B. PASSIOURA. 1993. Carbon gain in relation to water use: Photosynthesis in mangroves. In: Ecophysiology of Photosynthesis. SpringerVerlag, Berlin.247-259 pp.

BJÖRKMAN, O., B. DEMMIG, T. J. ANDREWS. 1988. Mangrove photosynthesis: Responses to high irradiance stress. Aust. J. Pl. Physiol. 15: 43 - 61.

CHOW, W. S., M. C. BALL, J. M. ANDERSON. 1990. Growth and photosynthetic responses of spinach to salinity: implications of $\mathrm{K}+$ nutrition for salt tolerance. Aust J Physiol. 17: 563 - 567.

CURTIS, S. J. 1993. Working plan for the forests of the Sundarbans Division for the 
period from Ist April 1931 to 3/st March 1961. Calcutta. India. Bengal Government Press. 175 pp.

DAS, S. 1999. An adaptive feature of some mangroves of Sundarbans, West Bengal. J Plant Biology 42(2): 109 - 116.

DELPHINE, S.,A. ALVINO, M. ZACCHINI, F. LORETO. 1998. Consequence of salt stress on conductance to $\mathrm{CO} 2$ diffusion, Rubisco characteristics of spinach leaves. Aust J Plant Physiol 25: 395 - 402.

GREENWAY, H., R. MUNNS. 1980. Mechanisms of salt tolerance in nonhalophytes. Ann Rev Plant Physiol. 31: 149-190.

HELDT, H. W. 1999. Plant Biochemistry and Molecular Biology. Oxford University Press.

JACKSON, M.L. 1973. Soil Chemical Analysis. Prentice Hall. New Delhi. India.

JANARDHAN, K. V., A. S. PARASHIVA MURTHY, K. GIRIRAJ, S. PANCHAKSHARAIAH. 1975. A rapid method for determination of osmotic potential of plant cell-sap. Current Science, 44 (11B): 390-391.

LEWIS, R. R.III. 2001. Mangrove restoration - cost and benefits of successful ecological restoration. Proc. of the mangrove valuation workshop.Universiti Sains Malaysia, Penang, 4 - 8 April, 2001.

LIN, G, L. DA, S. L. STERNBERG. 1993. Hydrogen isotopic fractionation by plant roots during water uptake in coastal wetland plants. In: Stable Isotopes and Plant Carbon-Water Relations. Academic Press, San Diego.497-510 pp.

MICHAEL, E. COMPTON, N. BARNETT and D. J. GRAY. 1999. Use of fluorescein diacetate (FDA) to determine ploidy of in vitro watermelon shoots. Plant Cell. Tissue and Organ Culture 58(3): 199 - 203.

NANDY DATTA, P., M. GHOSE. 2003. Estimation of osmotic potential and free amino acids in some mangroves of Sundarbans, India. Acta Botanica Croat 62(1): 37 45 .

NANDY DATTA, P., S. DAS, M. GHOSE. 2005. Relation of leaf micromorphology with photosynthesis and water efflux in some Indian mangroves. Acta Botanica Croat 64 (2): 331 - 340.

NASKAR, K.R., D.N. GUHA BAKSHI. 1983. A brief review on some less familiar plants of the Sundarbans India. J Econ and Taxonomic Bot 4(3): 699 - 712.

PARIDA, A.K., A.B. DAS, B. MITRA. 2004. Effect of salt and growth, ion accumulation. photosynthesis and leaf anatomy of the mangrove, Bruguiera parviflora. Trees. 
18: $167-174$.

PEOPLES, T.R., D.W. KOCH. 1979. Role of potassium in carbon dioxiderssimilation in Medicago sativa L. Plant Physiol 63: 878 - 881.

POPP, M., F. LARHER, P. WEIGEL. 1984.Chemical composition of Australian mangroves, III, Free amino acids, total methylated onium compounds and total nitrogen. Zietschrift Pflanzenphysiology, 114: 15 - 25.

POORTER, H., J. EVANS. 1998. Photosynthetic nitrogen use efficiency of species that differ inherently in specific leaf area. Oecologia. 116: 26 - 37.

RAO, T.A. 1985. The veinlet syndrome of certain mangroves: Proc Natl Symp Biol Util Cons. Mangroves, Shivaji University, Kholapur, India. 49-59 pp.

ŠANTRUCEK, J., E. ŠIMÁNOVÁ, J. KARBULKOVÁ, M. ŠIMKOVÁ, L. SCHREIBER 2004. A new technique for measurement of water permeability of stomatous cuticular membranes isolated from Hedera helix leaves. Journal of Experimental Botany, 55: 1411-1422.

SALISBURY, F.B., C.W. ROSS. 1995. Plant Physiology.-Wadsworth Publishing Co., Oxford.

SANYAL, P. 1996. Sundarbans: The largest mangrove diversity on globe. In: Willium Roxburgh Memorial Seminar on Sundarban Mangals, Calcutta. 11-26 pp.

SPERRY, J.S., M.T. TYREE, J.R. DONNELLY. 1988. Vulnerability of xylem to embolism in a mangrove vs an inland species of Rhizophoraceae. Physiol. Plant 74: 276-283.

VOLHARD, A. 1956. Modern method of plant analysis. Peach K and Tracey MV eds. Springer-Verlag, Berlin.

ZIMMERMANN, M.H. 1983. Xylem structure and the ascent of sap. Springer-Verlag, Berlin. 